walkers, those with GMFCS level II had lower BMD z-scores than children with level I at the distal femur ( $p$-values $<0.004$ ) but not in the LS $(p=0.06)$. Mean 25-OHD concentration was $45 \mathrm{nmol} / \mathrm{L}$ (SD: 18); lower in walkers (mean: $41 \mathrm{nmol} / \mathrm{L}$; SD: 18 ) than in non-walkers (mean: $53 \mathrm{nmol} / \mathrm{L}$; SD: 19; $\mathrm{p}=0.041$ ). There was no correlations between 25-OHD and BMD.

Conclusions The main predictor of low BMD was the inability to walk. Children with GMFCS level II had considerably lower BMD than children with level I. The majority of the CP children had insufficient vitamin D status; however, no correlation between vitamin D status and BMD was observed.

\section{PO-0829 ASSESSMENT OF BODY FAT PERCENTAGE IN CHILDREN WITH CEREBRAL PALSY}

${ }^{1}$ AK Finbråten, ${ }^{2} \mathrm{U}$ Syversen, ${ }^{1} \mathrm{~J}$ Skranes, ${ }^{3} \mathrm{G}$ Andersen, ${ }^{4} \mathrm{R}$ Stevenson, ${ }^{1} \mathrm{~T}$ Vik. ${ }^{1}$ Department of Laboratory Medicine Children's and Women's Health, Norwegian University of Science and Technology, Trondheim, Norway; ${ }^{2}$ Department of Cancer Research and Molecular Medicine, Norwegian University of Science and Technology, Trondheim, Norway; ${ }^{3}$ The Cerebral Palsy Register of Norway, Habilitation Center Vestfold Hospital, Tønsberg, Norway; ${ }^{4}$ Department of Pediatrics, University of Virginia, Charlottesville, USA

\subsection{6/archdischild-2014-307384.1462}

Background and aim Children with cerebral palsy (CP) have higher risk for malnutrition and poor growth; however, it is difficult to assess nutritional status. The aim was to assess body fat percentage based on anthropometric measurements and compare it with direct measurement of percentage body fat with dual Xray absorptiometry (DXA) in children with CP.

Methods Forty-seven children (age range: 8-18 years; 18 girls) with CP participated and had their body fat percentage measured using DXA. Body fat percentages were estimated from triceps and subscapular skinfolds using standard (Slaughter et al.) and CP-specific equations (Gurka et al.). Differences and agreement between DXA and skinfold body fat percentage were analysed by comparing mean differences by Bland-Altman plots.

Result The CP-specific equations $(r=0.883)$ and the standard equations $(r=0.819)$ had excellent correlation coefficient with DXA fat percent. The standard equations underestimated body fat percent (mean difference: $-7.1 \%$ ) measured by DXA (Figure 1). In contrast, the mean difference between fat percent

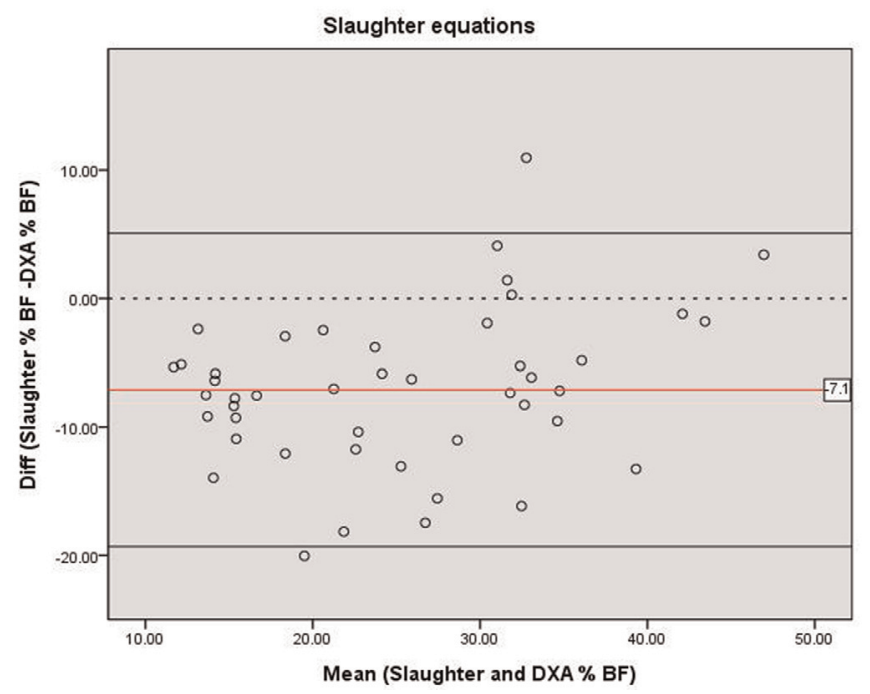

Abstract P0-0829 Figure 1

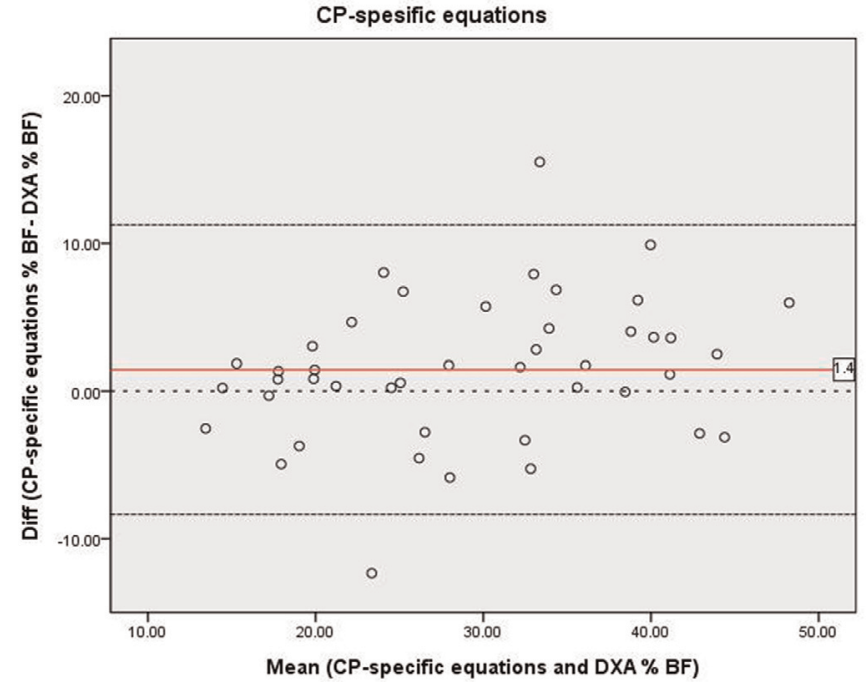

Abstract P0-0829 Figure 2

calculated by the CP-specific equations and by DXA differed marginally $(+1.4 \%)$ (Figure 2$)$.

Conclusion Accurate measures of body fat percentages may be obtained using two skinfold measurements with the CP-specific equations in children with CP.

\section{PO-0830 IS THERE ANY CORRELATION BETWEEN POLYMORPHISM C677T METHYLENETETRAHYDROPHOLATE REDUCTASE (MTHFR) GENE AND HOMOCYSTEINE LEVEL IN CEREBRAL PALSY?}

U Gamayani. Neurology, Faculty of Medicine Universitas Padjadjaran, Bandung, Indonesia

\subsection{6/archdischild-2014-307384.1463}

Background Cerebral palsy (CP) is common cause of disability in children. The aetiology of cerebral injury in CP is multifactorial, and recent studies suggested that genetic factor maybe contributed to the development of CP. Polymorphism C677T MTHFR gene influenced homocysteine metabolism that has neurotoxic effect.

Aim This is a preliminary study. The aim of this study was to evaluate the correlation between polymorphism C677T MTHFR gene and homocysteine level in CP children in Bandung, Indonesia.

Methods This is the cross sectional study. The CP children, 414 years old were analysed C677T polymorphism in the MTHFR gene and homocysteine level. The data of this study were analysed with SPSS program, t-tests were used, and statistical significance was defined as $\mathrm{p}$ value $\leq 0,05$.

Results Thirty six spastic CP children, GMFCS I-III (22 males and 14 females; mean age 9,8 years) from school for disability children at Cibiru and Suryakanti (centre for children with special needs) in Bandung, Indonesia. There is a heterozigote polymorphism C677T MTHFR gene in 7 children $(5$ males and 2 females). The mean of homocysteine level is 8,69 . We found no significant correlation between polymorphism C677T MTHFR gene and homocysteine level in CP children $(\mathrm{p}=0,89)$

Conclusion Preliminary data shows no correlation between polymorphism C677T MTHFR gene and homocysteine level in CP 
children in Bandung, Indonesia. However more subjects are required to further studies.

\section{PO-0831 CLINICAL, NEUROEPIDEMIOLOGICAL SPECTRUM AND TREATMENT OUTCOME OF WEST SYNDROME IN CHILDREN}

S Gannouni-ghariani, H Barakizou, A Ayari, Y Ben Rjeb, F Bayoudh. Paediatrics, Hôpital Militaire Principal d'instruction de Tunis, Tunis, Tunisia

10.1136/archdischild-2014-307384.1464

Problem West Syndrome (WS) is a severe epileptic disorder. Its aetiology is highly heterogeneous, the treatment is limited and the prognosis depends on the cause. Studies of this disease allowed the establishment of prognosis criteria and optimal therapeutic strategies.

of the work studying the diverse physiopathological, epidemiological, diagnostic, therapeutic and evolutionary aspects of this syndrome and comparing our results with literature to improve our coverage.

Methods We conducted a retrospective study on the observations of 30 children followed for WS in the department of paediatrics of the military hospital of Tunis between 1990 and 2010. The studied variables were: aetiology, treatments and their efficiency as well as neurological, cognitive and behavioural development of children.

Results The age of onset is before the first year in $93.33 \%$ of cases. The disease occurs mainly by epileptic spasms and almost all children presented a significant developmental regression. Typical hypsarythmia is found only in $36 \%$ of cases. Concerning aetiology, symptomatic forms represent $20 \%$ and idiopathic ones $10 \%$. The usual protocol at our department is to start with Vigabatrin-corticosteroid association with $91.6 \%$ efficiency. Neurological prognosis is severe with sequelas in $66.66 \%$ of cases. Behavioural disorders are also significant because half of children have mental retardation.

Conclusion Despite the existence of more effective molecules, the prognosis of the WS remains severe. Better knowledge of physiopathology, the deferent electroclinical aspects and therapeutic management allow improving the children's fate.

\section{PO-0832 EARLY PREDICTORS OF NEURODEVELOPMENTAL OUTCOME OF NEONATAL BACTERIAL MENINGITIS}

T Sirbiladze, N Adamia, M Ghughunishvili. Central Pediatric Clinic, Georgian State Medical Academy

\subsection{6/archdischild-2014-307384.1465}

154 Patients, who were hospitalised in M. Iashvili Childrens's central hospital in 1998-2005 were investigated. In 70 cases the diagnosis was neonatal bacterial meningitis, in 62 cases - bacterial sepsis and neonatal meningitis and 22 cases patients were in control group with the diagnosis of neonatal bacterial sepsis.

From base investigation group - 132 patients were divided in two groups, in which patients were united by the starting point of disease from the birth: first group included newborns with signs of disease on earlier stage (signs of the disease showed up during 24-72 h from the birth); Second group included newborns with later signs of disease (after $72 \mathrm{~h}$ from the birth).

Our conclusion is - outcome of bacterial meningitis depends on the starting point of disease. Meningitis which began earlier than $72 \mathrm{~h}$ of life, characterised by severe prognosis. Mother's chronical infection diseases and brain injury of newborn are predictors of severe complications of neonatal bacterial meningitis. Such complications of bacterial meningitis as are: brain abscess, ventriculitis, neonatal seizures, coma and neutropenia, become predictors of severe latest outcome.

\section{PO-0833 WITHDRAWN}

\section{PO-0834 LONG-TERM DEVELOPMENTAL OUTCOME OF CHILDREN PRENATALLY EXPOSED TO ANTIEPILEPTIC DRUGS}

${ }^{1} \mathrm{~N}$ Gogatishvili, ${ }^{1} \mathrm{~T}$ Ediberidze, ${ }^{1} \mathrm{G}$ Lomidze, ${ }^{2} \mathrm{~N}$ Tatishvili, ${ }^{1} \mathrm{~S}$ Kasradze. ${ }^{1}$ Epilepsy Centre, Institute of Neurology and Neuropsychology, Tbilisi, Georgia; ${ }^{2}$ Department of Neuroscience, M. lashvili Children Central Hospital, Tbilisi, Georgia

\subsection{6/archdischild-2014-307384.1466}

Background and aims The long-term effects of intra-uterine exposure antiepileptic drugs (AEDs) on cognitive functioning are limited and conflicting. The aim of the study was to assess the remote effects of fetal AEDs on cognitive outcomes in children. Methods Children, aged 2-4 years, with fetal exposure of carbamazepine (CBZ), lamotrigine (LTG) or valproate (VPA) monotherapy were recruited from the local registry of EpilepsyPregnancy. Neuropsychological assessment was performed in all cases with Learning Accomplishment Profile (LAP) for children of 1-6 years. All age groups were evaluated with Wide Range Assessment of Visual Motor Abilities (WRAVMA) tests. The results were compared to the results of the epidemiological study evaluating developmental achievements in general preschool children population.

Results In total 39 children were assessed. Eleven (28\%) were exposed to intra-uterine VPA, $22(56 \%)$ to CBZ and six (15\%) to LTG. From whole group poor performance in expressive speech was detected in nine persons $(23 \%$; 95\% CI 12\% - 44\%) and there were no cases with fetal exposure to LTG. Out of children with fetal-VPA exposure $(n=11)$ the speech problems were observed in three cases (27\%); from 22 children with CBZ intra-uterine exposure - in six (27\%); no significant deficits were revealed in other developmental milestones.

Conclusions The data of our study suggests that difficulties in verbal abilities are more often associated with fetal exposure to VPA and CBZ. For more conclusive results further profound neuropsychological evaluations are needed.

\section{PO-0835 WITHDRAWN}

\section{PO-0836 DETERMINATION OF COGNITIVE FUNCTIONING DISORDERS INCIDENCE IN CHILDREN WITH MULTIPLE SCLEROSIS}

${ }^{1} \mathrm{~K}$ Gücüyener, ${ }^{1} \mathrm{~S}$ Soysal, ${ }^{2} \mathrm{U}$ Yilmaz, ${ }^{3} \mathrm{E}$ Demir, ${ }^{4} \mathrm{E}$ Gurkas, ${ }^{3} \mathrm{C}$ Havali. ${ }^{1}$ Pediatric Neurology, Gazi University Faculty of Medicine, Ankara, Turkey; ${ }^{2}$ Pediatric Neurology, Behcet Uz Children's Hospital Izmir, Izmir, Turkey; ${ }^{3}$ Pediatric Neurology, Gazi University Faculty of Medicine, Ankara, Turkey; ${ }^{4}$ Pediatric Neurology, Ankara Childeren's Oncology Hematology Hospital, Ankara, Turkey

10.1136/archdischild-2014-307384.1467 